\title{
La experiencia política importa. Estabilidad partidaria a nivel subnacional en el Perú ${ }^{+}$
}

\author{
MANUEL SEIFERT* \\ Pontificia Universidad Católica del Perú \\ mseifert@pucp.pe \\ https://doi.org/10.18800/rcpg.201602.005
}

\section{RESUMEN}

El presente artículo busca aportar al estudio de la construcción partidaria en al ámbito subnacional en el Perú. Desde las elecciones regionales y municipales de 2002 hasta 2014, ha imperado un escenario de alta volatilidad y poco enraizamiento partidario. Solo diez organizaciones políticas regionales han logrado participar de forma consecutiva durante las elecciones de este período. Así, el trabajo explora cómo estas organizaciones políticas lograron ser estables y presentar ininterrumpidamente candidaturas a los procesos electorales subnacionales. Al indagar diversas dimensiones explicativas, se encuentra que la dimensión que mejor responde a esta interrogante es la experiencia política previa que tuvo la dirigencia al momento de constituir dichas organizaciones políticas regionales.

Palabras clave: Experiencia política, partidos políticos, ámbito subnacional, construcción partidaria, Perú.

\section{Political experience matters. Party Stability at the Subnational Level in Peru}

\begin{abstract}
This article seeks to contribute to the study of party-building in the subnational level in Peru. Since the regional and municipal elections from 2002 to 2014, there has been a scenario of high party volatility and low partisan rooting. Only ten (10) regional political parties have been able to participate consecutively during the elections of this period. Therefore, this document explores how these political organizations managed to be stable and to present without interruption candidacies to subnational electoral processes. When analyzing various explanatory dimensions, it is found that the dimension that best answers this question is the previous political experience that the leadership had at the time of establishing such regional political parties.
\end{abstract}

Key words: Political experience, Political parties, Subnational level, Party-building, Perú.

\footnotetext{
* Magíster en Ciencia Política y Gobierno por la Pontificia Universidad Católica del Perú.

+ Recibido el 25 de enero de 2017; aceptado el 10 de abril de 2017.
} 

La descentralización política se inició en el Perú luego de la transición democrática, la cual implicó la creación de nuevas autoridades a nivel regional, cuya designación se produjo con las primeras elecciones regionales y municipales (ERM) en el año 2002. Estas elecciones introdujeron un nuevo actor políticoelectoral: los partidos regionales' ${ }^{1}$.

Su participación en las ERM de 2002 fue tenue, sin mucha presencia a nivel regional, como provincial y distrital. Sin embargo, para las ERM de 2010 el escenario cambió completamente y se convirtieron en el actor hegemónico en los tres niveles de gobierno, ganando la mayoría de los cargos disputados. Las últimas ERM de 2014 solo han confirmado este dominio y han demostrado que los partidos nacionales han quedado relegados a un segundo plano a nivel subnacional.

Sin embargo, la gran mayoría de los partidos regionales han dejado de existir y no han logrado participar de manera consecutiva en las elecciones. El presente trabajo buscará comprender por qué solo diez partidos regionales en todo el Perú han logrado participar de manera consecutiva en todas las ERM (2002-2006-2010-2014). Al indagar sobre dicha interrogante, se encontrará que la experiencia política previa de los líderes de estas organizaciones políticas, al momento de constituirse, fue lo que cimentó las bases para alcanzar dicha estabilidad.

\section{CONSIDERACIONES PREVIAS ${ }^{2}$}

En las ERM de 2002, los partidos nacionales ganaron en 18 de las 25 regiones, mientras que a nivel provincial y distrital ganaron 55\% y $60 \%$ de los municipios respectivamente. Por otra parte, los partidos regionales ganaron en las 7 regiones restantes, y a nivel local ganaron en 16\% de los municipios provinciales y $12 \%$ de los municipios distritales. Para las ERM de 2014, los partidos nacionales habían ganado en tan solo 6 regiones, y a nivel provincial y distrital ganaron $24 \%$ y $31 \%$ de los municipios respectivamente; mientras que los partidos regionales habían ganado en 18 de las 25 regiones, el $72 \%$ de los municipios provinciales y el $61 \%$ de los municipios distritales. Este claro dominio de

\footnotetext{
1 Según la normativa peruana, estos son catalogados como movimientos regionales. Sin embargo, partiendo de una definición mínima de partido político (grupo político que presenta o quisiera presentar candidatos a cargos públicos) se utilizará indistintamente a lo largo del texto como conceptos intercambiables los partidos regionales y organizaciones políticas regionales.

2 El problema de cómo este desempeño afectará a la representación de los ciudadanos no será abarcado en el presente trabajo, a pesar de reconocer su vital importancia y relación estricta con los partidos políticos.
} 
los partidos regionales, presente ya desde las ERM 2010, hace de vital importancia prestarles mayor atención al momento de estudiar la problemática de los partidos políticos en el Perú.

Cuadro 1. Triunfos electorales de los partidos nacionales y regionales en las ERM de 2002-2014 según los niveles de gobierno

\begin{tabular}{|l|c|c|c|c|c|c|c|c|}
\hline \multirow{2}{*}{ Nivel } & \multicolumn{4}{|c|}{ Partidos nacionales } & \multicolumn{4}{c|}{ Partidos regionales } \\
\cline { 2 - 9 } & 2002 & 2006 & 2010 & 2014 & 2002 & 2006 & 2010 & 2014 \\
\hline Presidencias regionales & $72 \%$ & $28 \%$ & $20 \%$ & $24 \%$ & $28 \%$ & $72 \%$ & $80 \%$ & $72 \%$ \\
\hline Municipios provinciales & $55 \%$ & $47 \%$ & $32 \%$ & $24 \%$ & $16 \%$ & $45 \%$ & $65 \%$ & $72 \%$ \\
\hline Municipios distritales & $60 \%$ & $55 \%$ & $36 \%$ & $31 \%$ & $12 \%$ & $34 \%$ & $60 \%$ & $61 \%$ \\
\hline
\end{tabular}

Fuente: ONPE. Elaboración propia.

Sin embargo, este auge de los partidos regionales no vino acompañado de una estabilidad y permanencia en sus circunscripciones respectivas. Durante las ERM de 2002 a 2010 se presentó una alta volatilidad partidaria a nivel subnacional (Seifert, 2014). La volatilidad partidaria considera como partido nuevo a todo aquel que no participó en la elección inmediatamente previa a la que se está presentando. Así, durante este período, dos tercios de los partidos que participaban en una elección no habían participado en las elecciones previas. En las elecciones de 2006 un promedio de 63,2\% eran partidos nuevos y para las elecciones de 2010 un 68,3\% de los partidos que presentaron candidaturas fueron nuevos también (Seifert, 2014, pp. 45-52).

Ahora, al promediar estas cifras con las ERM de 2014 (Gráfico 1) vemos que de una elección a otra elección, un $64 \%$ son partidos nuevos. Esta situación conlleva a que se le haga muy fácil al elector cambiar su voto y elija otro partido o, viceversa, que le sea muy difícil mantenerse fiel a uno solo. Este escenario de alta volatilidad partidaria hace que la construcción de una lealtad partidaria se vuelva sumamente difícil. Por más que la demanda electoral quisiera volver a votar por el mismo partido, existen altas probabilidades de que no pueda hacerlo porque el partido salió del mercado y fue reemplazado por otro $^{3}$.

\footnotetext{
3 Para conocer el nivel de enraizamiento que una organización política obtiene en un determinado proceso electoral confróntese con Incio y Gil (2016).
} 


\section{Gráfico 1. Promedio de volatilidad partidaria entre las ERM de 2002 a 2014}

- Partidos Nuevos - Partidos constantes

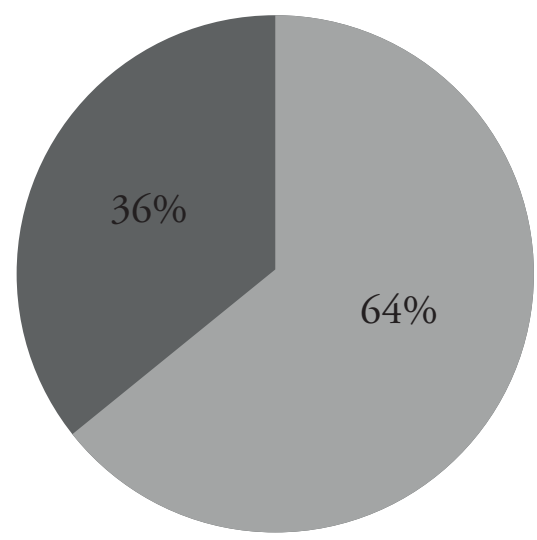

Fuente: JNE. Elaboración propia.

\section{ESTABILIDAD PARTIDARIA REGIONAL}

Como hemos podido ver hasta este punto, la estabilidad partidaria es algo poco frecuente en las elecciones subnacionales en el Perú. Desde las primeras elecciones regionales y municipales en el año 2002, han existido un total de 422 partidos regionales ${ }^{4}$. No obstante ello, solo diez organizaciones políticas regionales lograron ser constantes y presentar candidaturas de manera consecutiva en las ERM de 2002 a 20145. Estos partidos regionales están presentes en ocho departamentos (Cuadro 2) y participaron en los procesos electorales subnacionales de forma ininterrumpida en cada una de sus circunscripciones.

Ahora bien, ¿cómo lograron estas diez organizaciones políticas participar de forma ininterrumpida en todas las ERM? ¿Qué elementos permitieron que estos partidos logren presentar candidaturas en todas las ERM?

\footnotetext{
Actualmente existen inscritos 128 movimientos regionales en el Jurado Nacional de Elecciones.

5 Los partidos regionales Autogobierno Ayllu (Cusco) y Poder Democrático Regional (Puno) han estado presentes desde 2002 y continúan vigentes. No obstante ello, en el primer caso, el Autogobierno Ayllu era una organización política de alcance local y no regional en las ERM de 2002; mientras que en el segundo, el Poder Democrático Regional, no presentó de forma consecutiva candidaturas en cada una de las ERM.
} 
Cuadro 2. Presencia de partidos regionales según departamento

\begin{tabular}{|l|l|}
\hline \multicolumn{1}{|c|}{ Departamento } & \multicolumn{1}{c|}{ Partidos regionales } \\
\hline Callao & 1. Chimpum Callao \\
\hline Cusco & 2. Movimiento Regional Inka Pachakuteq \\
\hline Huánuco & 3. Luchemos por Huánuco \\
\hline Loreto & $\begin{array}{l}\text { 4. UNIPOL } \\
\text { 5. Fuerza Loretana }\end{array}$ \\
\hline Pasco & 6. Concertación en la Región \\
\hline San Martín & 7. Nueva Amazonía \\
\hline Tumbes & $\begin{array}{l}\text { 8. Reconstrucción con obras más obras para un Tumbes más bello } \\
\text { 9. Movimiento Independiente Regional FAENA }\end{array}$ \\
\hline Tacna & 10. Alianza por Tacna \\
\hline
\end{tabular}

Fuente: JNE. Elaboración propia.

La construcción partidaria es entendida como el proceso a través del cual un partido político nace, participa en procesos electorales y es estable a lo largo del tiempo para enraizarse en la sociedad. Asimismo, se puede considerar que a lo largo de este proceso el partido político se convierte en un actor constante y significativo en la sociedad a la que ingresa (Levitsky, Loxton, Van Dyck y Domínguez, 2016). Las razones que llevan a que un partido político se consolide como una organización duradera pueden ser varias, desde factores institucionales (reglas de juego que posibiliten su permanencia) hasta estructurales.

El presente trabajo no hará (ni busca hacer) un repaso exhaustivo de estas diversas razones explicativas, mas si señalará cómo algunas de estas muestran limitaciones al momento de explicar la estabilidad partidaria subnacional para cada una de estas organizaciones políticas en sus territorios correspondientes. Es un análisis exploratorio que decide indagar diversas dimensiones que pudieran echar luz sobre esta situación. Al momento de realizar esta indagación, se encontró que la experiencia política previa que tuvo la dirigencia del partido al momento de constituirse como organización, es la dimensión que mejor logra explicar (y agrupar) al conjunto de partidos regionales. 


\section{Figura 1. Departamentos en donde los partidos regionales han logrado participar de} manera consecutiva en las ERM (2002 a 2014)

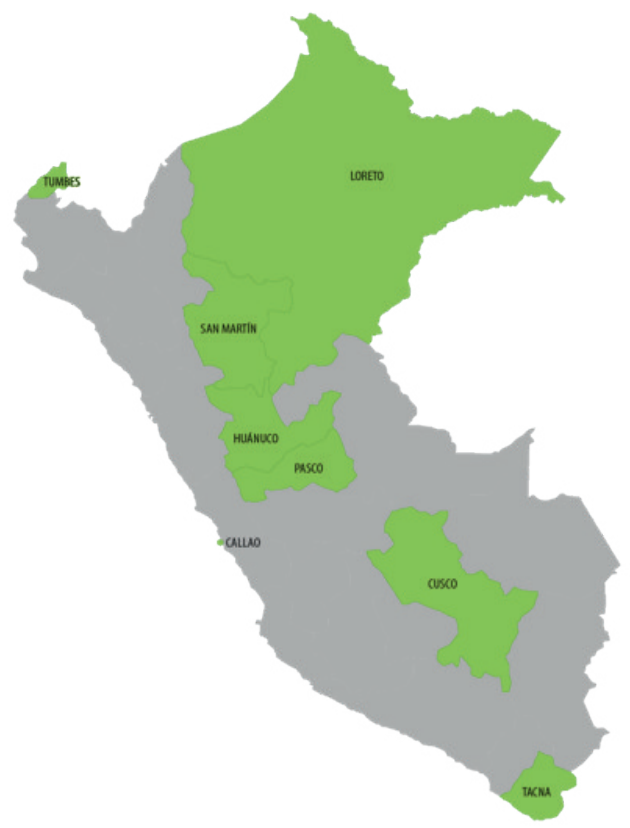

Fuente: JNE. Elaboración propia.

\section{Diseño institucional - Reglas de JUego}

Las instituciones moldean y configuran el comportamiento de las personas. Estas establecen y delimitan el campo de acción de los individuos, creando restricciones y libertades. Un sistema electoral, que son las normas a través de las cuales los votos serán convertidos en escaños (o puestos públicos), establece un conjunto de reglas que moldearán el comportamiento de las organizaciones políticas dentro del mismo. Así, estas reglas pueden fomentar la creación de partidos y promover su estabilidad, mientras que otro set de reglas puede aumentar los costos de participación en los procesos electorales. Según Mainwaring y Scully (1999), las reglas establecidas en el sistema electoral proporcional brasileńo produjeron el debilitamiento de los partidos.

En el caso peruano, la Ley de Partidos Políticos estableció claras diferencias para la creación y participación de las organizaciones políticas, según el alcance que tuvieran. Los partidos regionales tuvieron requisitos más laxos que los partidos nacionales para presentar candidaturas para las ERM, lo que conllevó a un debilitamiento de los partidos nacionales (Tanaka, 2009; Vergara, 2009; 
Meléndez, 2008; Seifert, 2014). Sin embargo, tomando en consideración que las mismas normas se aplicaban para cada una de las regiones, este enfoque presenta serias limitaciones para comprender por qué en Huánuco un partido logró presentar candidaturas de manera consecutiva durante las cuatro ERM pero que esto no fue posible en Áncash, Ayacucho, Cajamarca, Ucayali, entre otros. Las reglas y los incentivos fueron los mismos para todas las circunscripciones a nivel subnacional y, sin embargo, solo diez partidos lograron participar consecutivamente desde 2002 en las ERM.

\section{RiQueZA REgIONAL}

Mantener una organización política es costoso. La falta de recursos financieros es uno de los principales (sino el principal) problema organizativo que enfrentan los partidos políticos. La ausencia de financiamiento público para partidos regionales, genera que estas sean sostenidas por fuentes privadas. Un partido político que no tenga suficiente capital para sobrellevar y sobrevivir durante las campañas, no podrá sostenerse por mucho tiempo.

En ese sentido, muchos partidos políticos no logran sobrevivir porque carecen de los recursos financieros (tanto desde su dirigencia como de su militancia) para lograr sostener una maquinaria electoral. La construcción partidaria requiere que la organización política, durante época no electoral, pueda tener ingresos suficientes para mantener una oficina con un personal fijo. El mantenimiento de una oficina partidaria a nivel regional es casi una ilusión. Los procesos electorales activan dichas oficinas, mas acabado el proceso estas dejan de existir (Zavaleta, 2014). Este tipo de ingreso destinado a la construcción de un partido en época no-electoral es considerado 'soft money' (Kolodny, 2012). Por otra parte, el número de militantes de una organización política regional es reducido y ya no es comparable con aquellos partidos de masas, donde el gran número de militantes podían sostener dicha carga financiera.

Bajo este escenario, los partidos regionales pueden ser financiados únicamente por fuentes privadas. Por ello, se decidió considerar el nivel de riqueza regional como una dimensión que podría dar luces sobre este fenómeno. Así, tomando en consideración que un partido regional está circunscrito a un departamento específico, el nivel socioeconómico de una región suele tener un impacto sobre los recursos con los que podría contar una organización política para participar en los procesos electorales y sobrevivir durante época no-electoral.

Sin embargo, esta dimensión tampoco logra agrupar al conjunto de departamentos. Por un lado tenemos a Huánuco, Loreto o Pasco con niveles 
de pobreza por encima del 40\%. Por el otro lado, están Callao o Tumbes cuyo nivel de pobreza es 8 y $11 \%$ respectivamente. Si los partidos solo pueden sostenerse con fuentes privadas, un departamento con altos niveles de pobreza dificulta y reduce la capacidad de obtener ingresos, soft money, para construir partidos regionales estables.

\section{Geografía}

La dificultad del terreno donde los partidos políticos tienen que hacer campañas y política suele ser considerado como un factor que influye en la construcción partidaria. Un mayor porcentaje de población rural, implica necesariamente que la población no se encuentra centralizada sino más bien dispersa y alejada de los centros urbanos. Esta dispersión conlleva a la necesidad de tener una mejor organización partidaria para que, de este modo, se pueda llegar a la gran población alejada.

Así, bajo esta visión, departamentos con población mayoritariamente rural podrían influir en la necesidad de construir partidos con una militancia para que hagan "trabajo de hormiga» ${ }^{6}$ para la recolección de votos y preferencias. Partidos que requieren de una organización territorial estructurada para la captación de votos y simpatizantes, tienen mayor probabilidad de perdurar como partidos (Levitsky, 2003; Samuels, 2006; De Gramont, 2010). Sin embargo, este factor tampoco termina siendo satisfactorio. Departamentos mayoritariamente urbanos como Tumbes o Callao han tenido partidos que han persistido en las cuatro elecciones, al igual que Huánuco o Loreto que son departamentos con un alto porcentaje de población rural.

\section{Conflictos}

Partidos surgidos de momentos históricos polarizantes y conflictivos han logrado sobrevivir a lo largo de los años. Este no solo es el caso del APRA, sino se ha repetido a lo largo de la historia latinoamericana, como el PRI en México, Alianza Republicana Nacionalista en El Salvador, el Partido por la Democracia en Chile (Levitsky, Loxton, Van Dick y Domínguez, 2016). Bajo

\footnotetext{
6 El «trabajo de hormiga» se entienden como las actividades que realiza la organización política desde su militancia a través de incidencia política en las diversas circunscripciones que participa. Suele ser una estrategia que no descansa tanto en el alcance de los medios de comunicación (radio, televisión o redes sociales), sino más bien en la cooptación de voto en un trabajo que se hace de puerta en puerta, con ferias, eventos, trabajos de cercanía con la población, lo cual implica la necesidad de una construcción organizativa más ordenada y constituida para llevar a cabo dichas actividades.
} 
esta misma visión estructural, los procesos conflictivos por los que ha pasado un país y el rol que jugaron los partidos durante los mismos, conlleva a que los partidos construidos bajo estos procesos suelan ser más duraderos (Levitsky et al., 2016). Asimismo, la persecución que sufren los líderes de estos partidos ayuda a generar una mayor cohesión entre su militancia y se termina armando una mística alrededor de ellos?

No obstante ello, al analizar esta dimensión en todos los departamentos se vuelve a encontrar marcadas diferencias entre las regiones. Según el reporte de la Defensoría del Pueblo, durante los años 2004-2014 lugares como Tacna, Pasco o Tumbes han tenido un nivel muy bajo de conflictividad (durante esos años), mientras que otros como Loreto han sufrido varios episodios conflictivos en los últimos años. Así, tampoco esta dimensión termina por explicar satisfactoriamente las razones de estabilidad entre los partidos regionales.

\section{7. ÉXITO ELECTORAL}

El éxito electoral que podría tener una organización política tampoco tiene una correlación con la estabilidad partidaria. En el caso de estas organizaciones políticas, existen organizaciones con victorias contundentes, como el caso de Chimpum Callao con tres presidencias regionales ganadas de forma consecutiva, o Fuerza Loretana y Nueva Amazonía con dos presidencias regionales consecutivas y varias alcaldías durante las ERM 2006 y 2010.

Por otro lado, existen organizaciones con un bajo nivel de éxito electoral como el partido FAENA, el cual solo obtuvo la presidencia regional en las ERM 2006, pero no ganó ninguna alcaldía provincial o distrital en ninguna de las elecciones. Asimismo, Reconstrucción con obras más obras para un Tumbes Bello no obtuvo ninguna presidencia regional, al igual que Inka Pachacuteq, y tuvo solo cuatro alcaldes elegidos durante este período.

El desempeńo electoral es desigual entre cada una de estas organizaciones y, si bien ocho de las diez organizaciones han ganado una presidencia regional a lo largo de este período, el éxito a nivel local se desvanece.

\footnotetext{
Esta situación permite explicar, en parte, las razones por las cuales el «fujimorismo» es la principal fuerza política en el Perú.
} 
Cuadro 4. Presidencias regionales, alcaldías provinciales y distritales obtenidas, ERM 2002-2014

\begin{tabular}{|l|l|c|c|c|c|c|c|c|c|c|c|c|c|c|}
\hline & & \multicolumn{3}{|c|}{ ERM 2002 } & \multicolumn{3}{c|}{ ERM 2006 } & \multicolumn{3}{c|}{ ERM 2010 } & \multicolumn{3}{c|}{ ERM 2014} \\
\hline Región & \multicolumn{1}{|c|}{ Partido político } & P & AP & AD & P & AP & AD & P & AP & AD & P & AP & AD \\
\hline Callao & Chimpum Callao & & 1 & 2 & 1 & 1 & 3 & 1 & 1 & 3 & 1 & & \\
\hline Cusco & Inka Pachakuteq & & 1 & 14 & & 1 & 3 & & 1 & 4 & & 1 & 8 \\
\hline Huánuco & Luchemos por Huánuco & 1 & 3 & 1 & & & 4 & & 2 & 6 & & & 3 \\
\hline Loreto & UNIPOL & 1 & 2 & 5 & & & 3 & & & & & & \\
\hline Loreto & Fuerza Loretana & & & 4 & 1 & 2 & 10 & 1 & 2 & 20 & & 3 & 13 \\
\hline Pasco & $\begin{array}{l}\text { Concertación en la } \\
\text { región }\end{array}$ & 1 & & 1 & & 1 & 5 & & & 4 & & 1 & 3 \\
\hline $\begin{array}{l}\text { San } \\
\text { Martín }\end{array}$ & $\begin{array}{l}\text { Nueva Amazonía } \\
\text { Tacna }\end{array}$ & Alianza por Tacna & & & 1 & 1 & 1 & 2 & & & 1 & & & \\
\hline Tumbes & $\begin{array}{l}\text { Reconstrucción con } \\
\text { obras }\end{array}$ & & 1 & & & & & & & 2 & & & 1 \\
\hline Tumbes & FAENA & & & & 1 & & & & & & & & \\
\hline
\end{tabular}

Fuente: JNE. Elaboración propia.

\section{EXPERIENCIA POLÍ́TICA}

La experiencia política previa de la dirigencia de los partidos regionales al momento de constituirse como organización política, será la dimensión que permita explicar de manera comprehensiva la estabilidad partidaria a nivel subnacional. Esta sería el común denominador que explicaría de mejor manera por qué lograron estos partidos regionales ser constantes a lo largo del tiempo.

Bajo la presidencia de Alejandro Toledo se aprueba la Ley de Elecciones Regionales (ley 27683). Esta fue publicada el 15 de marzo de 2002 y establecía que la elección de las autoridades regionales se realizaría junto con las elecciones municipales, el primer domingo del mes de octubre. Desde la publicación de esta norma y tomando en consideración el tiempo que tendría una organización política regional para inscribirse y participar en las elecciones, estas contaban con un lapso de tiempo de alrededor de 120 días. Este ajustado tiempo no dejó mucho margen para que los partidos puedan inscribirse, organizarse, presentar listas de candidaturas y participar en las elecciones. 
Este poco tiempo para la preparación ya no estuvo presente para las siguientes elecciones. Los futuros líderes de nuevos partidos regionales tuvieron mayor tiempo para adecuarse a la normativa y prepararse para las elecciones. De las ERM de 2002 a las ERM de 2006, el número de partidos regionales que presentaron candidaturas aumentó en 111\% (Gráfico 2). Luego, en las elecciones venideras, al contar con más tiempo para la preparación, el número de partidos regionales se fue incrementando de elección a elección (Seifert, 2014).

Gráfico 2. Número de partidos regionales según ERM (2002-2014)

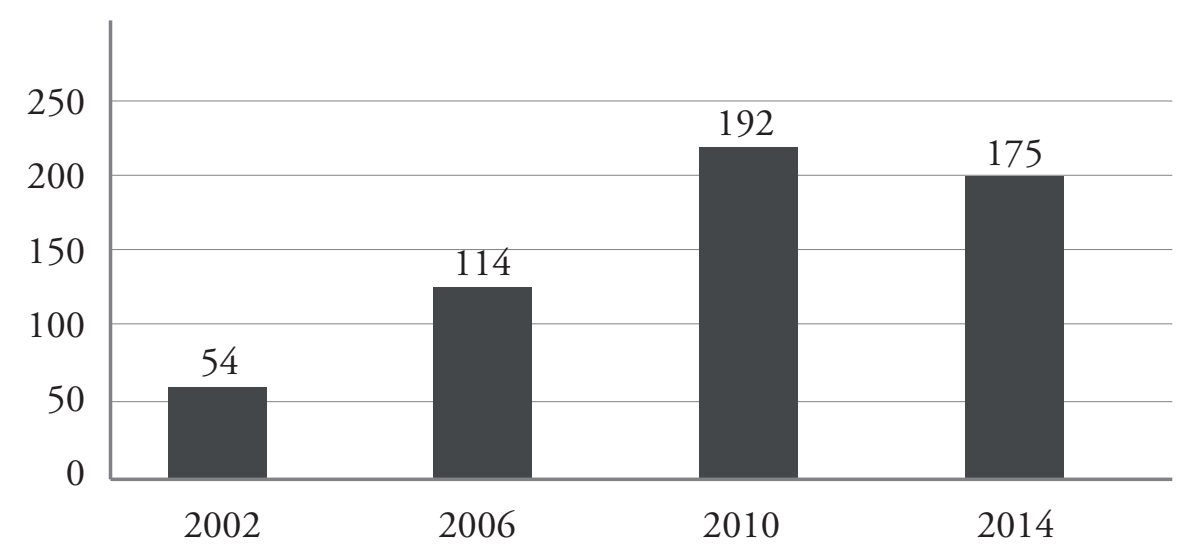

Fuente: JNE. Elaboración propia.

Ahora bien, cuando convocaron las primeras ERM de 2002 y existía la posibilidad de participar con una nueva organización que no cargara con taras históricas y organizativas como los partidos nacionales (Seifert, 2014; Zavaleta, 2014), una dirigencia que ya contaba con historia y experiencia política previa decidió conformar sus partidos.

Estamos considerando como experiencia política a todo aquel que haya participado en procesos electorales como candidato(a) a cualquier cargo y/o haya ejercido cargos públicos de elección popular. Operacionalizar el concepto, establecer una gradación del mismo y construir indicadores, para conocer los distintos niveles de experiencia política, está relacionado con la construcción de perfiles políticos antes que con la intención del presente trabajo. Basta con esta definición mínima para poder responder a nuestra interrogante.

Haber participado en procesos electorales previos es una constante en todos los dirigentes de las organizaciones políticas que han presentado candidaturas de forma consecutiva en todas las ERM. La gran mayoría tiene más de dos procesos electorales previos (Cuadro 5). Han postulado a regidurías, 
alcaldías locales y provinciales, Congreso y Senado de la República, hasta a la Vicepresidencia de la República. Por ejemplo, Yvan Vasquez de Fuerza Loretana, del departamento de Loreto, postuló a la segunda vicepresidencia de la República en las Elecciones Generales de 2006. Asimismo, la gran mayoría de los presidentes y fundadores de los partidos regionales han sido regidores, alcaldes distritales y provinciales, y hasta congresistas de la República.

Cuadro 5. Experiencia política previa de los líderes de los partidos regionales a las ERM 2002

\begin{tabular}{|l|l|}
\hline Número de procesos electorales previos & \multicolumn{1}{|c|}{ Líderes/as } \\
\hline Un proceso electoral & Florentino Laime (Cusco) \\
\hline Dos procesos electorales & $\begin{array}{l}\text { Yvan Vasquez (Loreto), Víctor Espinoza (Pasco), César } \\
\text { Villanueva (San Martín) }\end{array}$ \\
\hline Tres procesos electorales & $\begin{array}{l}\text { Luzmila Templo (Huánuco), Robinson Rivadeneyra } \\
\text { (Loreto), Hugo Ordóńez (Tacna), Ricardo Flores (Tumbes) }\end{array}$ \\
\hline Cuatro procesos electorales & Alexander Kouri (Callao) \\
\hline
\end{tabular}

Fuente: JNE. Elaboración propia.

Ahora bien, un aspecto a considerar es que varios de los políticos no solo habían postulado a diversos cargos de elección popular, sino que al menos en tres casos estos habían formado organizaciones políticas de alcance local antes de las ERM de 2002. Es decir, ya tenían experiencia en la construcción partidaria a nivel provincial y luego replicarían dicha experiencia para la construcción de partidos regionales.

En el caso de Callao, el político Alexander Kouri habría participado en las elecciones municipales de 1995 y 1998 con su organización política de alcance local Chim Pum Callao. Luego, para las ERM transformaría dicha organización local en partido regional bajo el rótulo Movimiento Político Independiente Chim Pum Callao. Por otra parte, en el caso de Huánuco, la política Luzmila Templo fue elegida alcaldesa provincial de Huánuco con la organización política de alcance local Movimiento Independiente Huánuco, que ella fundó y sería reelegida con su nueva organización L.I. Nro 9. Así, para las ERM de 2002, cuando decidió conformar el partido regional Movimiento Independiente Luchemos por Huánuco, ya tenía una experiencia en la construcción partidaria y pudo adecuarse a los requisitos para inscribirse, presentar candidaturas y participar en las ERM de 2002. Por último, en el caso de Fuerza Loretana, su presidente fundador Yvan Vásquez, había ingresado a la política postulando como diputado en las 
elecciones generales de 1990. Sin embargo, será recién en 1998, cuando constituye su organización política de alcance local Fuerza Loretana, que es elegido alcalde provincial de Maynas. Este mismo membrete partidario será utilizado cuando constituya su partido regional en las ERM de $2002^{8}$.

\section{Cuadro 6. Experiencia política previa según partido}

\begin{tabular}{|c|c|c|}
\hline & Partido político & Experiencia política previa \\
\hline Callao & $\begin{array}{l}\text { 1. Chimpum } \\
\text { Callao }\end{array}$ & $\begin{array}{l}\text { 1. Alexander Martin Kouri Bumachar (presidente fundador - PF) } \\
\text { - } 1989 \text { postula como regidor provincial para Lima (FREDEMO) } \\
\text { - } 1992 \text { Congresista Constituyente (PPC) } \\
\text { - } 1995 \text { Alcalde Provincial del Callao (Chimpum - Callao) } \\
\text { - } 1998 \text { Alcalde Provincial del Callao (Chimpum - Callao) } \\
\text { - } 2002 \text { Alcalde Provincial del Callao (Mov. Pol. Ind. Chimpum Callao) } \\
\text { - } 2006 \text { Presidente Regional del Callao (Mov. Ind. Chimpum Callao) } \\
\text { - } 2010 \text { postuló a la Alcaldía Provincial de Lima (Cambio Radical) } \\
\text { - } 2011 \text { postuló al Congreso de la República (Cambio Radical) }\end{array}$ \\
\hline Cusco & $\begin{array}{l}\text { 2. Inka } \\
\text { Pachakuteq }\end{array}$ & $\begin{array}{l}\text { 2. Florentino Laime Mantilla (Secretario General - SG y Fundador - F) } \\
\text { - } 1998 \text { Alcalde Provincial de Chumbivilcas (Mov. Nuevo Chumbivilcas) } \\
\text { - } 2002 \text { y } 2010 \text { postuló a la Alcaldía Provincial de Chumbivilcas (Inka } \\
\text { Pachakuteq) } \\
\text { - } 2010 \text { Alcalde Provincial de Chumbivilcas } \\
\text { - } 2014 \text { postuló a la reelección. }\end{array}$ \\
\hline Huánuco & $\begin{array}{l}\text { 3. Luchemos } \\
\text { por Huánuco }\end{array}$ & $\begin{array}{l}\text { 3. Luzmila Templo Condeso (Presidente) } \\
\text { - } 1993 \text { Alcaldesa Provincial de Huánuco (Movimiento Independiente Huánuco) } \\
\text { - } 1995 \text { Alcaldesa Provincial de Huánuco (L.I. Nro 9) } \\
\text { - } 1998 \text { quiso ser reelegida con Vamos Vecinos } \\
\text { - } 2002 \text { Presidenta Regional Huánuco } \\
\text { - } 2006 \text { y } 2010 \text { postula a la Presidencia sin éxito. }\end{array}$ \\
\hline \multirow[t]{2}{*}{ Loreto } & 4. UNIPOL & $\begin{array}{l}\text { 4. Robinson Rivadeneyra Reátegui (F) } \\
\text { - } 1989 \text { postuló como regidor a la provincia de Maynas (IU) } \\
\text { - } 2000 \text { Congresista (Perú Posible) } \\
\text { - } 2001 \text { postuló al Congreso por Loreto (UPP) } \\
\text { - } 2002 \text { Presidente Regional Loreto (UNIPOL) } \\
\text { - } 2006 \text { y } 2010 \text { postuló a la presidencia regional Loreto (UNIPOL) }\end{array}$ \\
\hline & $\begin{array}{l}\text { 5. Fuerza } \\
\text { Loretana }\end{array}$ & $\begin{array}{l}\text { 5. Yván Enrique Vásquez Valera (PF) } \\
\text { - } 1990 \text { postuló a las elecciones generales como diputado (Movimiento } \\
\text { Regionalista Loreto) }\end{array}$ \\
\hline
\end{tabular}

8 Esta línea de construcción partidaria regional también se repitió con el hoy partido regional Autogobierno Ayllu. Este partido se originó como organización política de alcance local en las ERM 2002 y luego, para las ERM de 2006, se constituyó como partido regional. Al igual que con los casos estudiados, la experiencia política previa de sus fundadores fue fundamental para asegurar la estabilidad partidaria de esta organización, la cual participó consecutivamente en las tres ERM venideras como partido regional (Bellatin, 2014). 


\begin{tabular}{|c|c|c|}
\hline & Partido político & Experiencia política previa \\
\hline & & $\begin{array}{l}\text { - } 1998 \text { Alcalde Provincial Maynas (Fuerza Loretana) } \\
\text { - } 2002 \text { postuló a la presidencia regional de Loreto (Fuerza Loretana) } \\
\text { - } 2006 \text { postuló como segundo vicepresidente de la República (Fuerza } \\
\text { Democrática) } \\
\text { - } 2006 \text { y } 2010 \text { Presidente Regional Loreto (Fuerza Loretana) }\end{array}$ \\
\hline Pasco & $\begin{array}{l}\text { 6. Concertación } \\
\text { en la región }\end{array}$ & $\begin{array}{l}\text { 6. Víctor Raúl Espinoza Soto (F) } \\
\text { - } 1986 \text { postuló como regidor al distrito de Yanacancha (L.I. Unidad y } \\
\text { Desarrollo Iqueńo) } \\
\text { - } 1993 \text { postuló a la Alcaldía Provincial Pasco (Frente de Desarrollo Cáceres) } \\
\text { - } 2002 \text { Presidente Regional Pasco (Concertación) } \\
\text { - } 2006 \text { quiso ser reelegido Presidente (Concertación) } \\
\text { - } 2011 \text { postuló al Congreso por Pasco (Alianza por el Gran Cambio) } \\
\text { (En } 2010 \text { postuló Valentín López Espíritu - tiene experiencia) }\end{array}$ \\
\hline $\begin{array}{l}\text { San } \\
\text { Martín }\end{array}$ & $\begin{array}{l}\text { 7. Nueva } \\
\text { Amazonía }\end{array}$ & $\begin{array}{l}\text { 7. César Villanueva Arévalo (PF) } \\
\text { - } 1980 \text { postuló como diputado de San Martín (Unidad Democrática Popular) } \\
\text { - } 2001 \text { postuló como congresista de San Martín (Mov. Independiente } \\
\text { Somos Perú - Causa Democrática) } \\
\text { - } 2002 \text { postuló a la Presidencia Regional San Martin (Nueva Amazonía) } \\
\text { - } 2006 \text { y } 2010 \text { Presidente Regional San Martín (Nueva Amazonía) }\end{array}$ \\
\hline Tacna & $\begin{array}{l}\text { 8. Alianza por } \\
\text { Tacna }\end{array}$ & $\begin{array}{l}\text { 8. Hugo Froilan Ordóñez Salazar } \\
\text { - } 1980 \text { Alcalde Provincial de Tacna (Lista Independiente No 3). } \\
\text { - } 1985 \text { postuló como senador de Tacna (Alianza Electoral Izquierda Unida). } \\
\text { - } 1989 \text { postuló a la Alcaldía Provincial de Tacna (Frente Unitario Popular). } \\
\text { - } 2002 \text { postuló a la Presidencia Regional de Tacna } \\
\text { - } 2006 \text { Presidente Regional de Tacna } \\
\text { - } 2014 \text { postuló a la Presidencia Regional de Tacna }\end{array}$ \\
\hline Tumbes & $\begin{array}{l}9 . \\
\text { Reconstrucción } \\
\text { con obras más } \\
\text { obras para un } \\
\text { Tumbes Bello }\end{array}$ & $\begin{array}{l}\text { 9. Ricardo Isidro Flores Dioses (PF) } \\
\text { - } 1993 \text { Alcalde Provincial Tumbes (Reconstrucción Tumbes) } \\
\text { - } 1995 \text { Alcalde Provincial Tumbes (L.I. Reconstrucción) } \\
\text { - } 1998 \text { postuló a la reelección (Vamos Vecino) } \\
\text { - } 2002 \text { Alcalde Provincial Tumbes (Reconstrucción para un Tumbes Bello) } \\
\text { - } 2006 \text { postuló a la Presidencia Regional (Reconstrucción para un Tumbes Bello) } \\
\text { (En } 2002 \text { postuló a la Presidencia Miguel Santiago Cappelletti Díaz - sin } \\
\text { experiencia) } \\
\text { (En } 2010 \text { postuló a la Presidencia Otto Walter Carrasco Zapata - } \\
\text { experiencia previa como candidato en 2006) }\end{array}$ \\
\hline & \begin{tabular}{l|}
10. \\
Movimiento \\
Independiente \\
Regional Faena
\end{tabular} & $\begin{array}{l}\text { 10. Wilmer Florentino Dios Benites (PF) } \\
\text { - } 2002 \text { postuló a la Presidencia Regional Tumbes (FAENA) } \\
\text { - } 2006 \text { Presidente Regional (FAENA) } \\
\text { - } 2010 \text { postuló a la Presidencia Regional } \\
\text { (Experiencia principalmente en el ámbito privado) }\end{array}$ \\
\hline
\end{tabular}


Ahora bien, la única excepción que confirmaría la regla es el caso del político Wilmer Dios Benites en Tumbes. Este no tuvo experiencia política previa, sino que más bien venía del ámbito privado y es ingeniero de formación. Este decide participar en política en las ERM de 2002, fundando el partido regional FAENA.

En suma, encontramos que la experiencia política previa de los presidentes y fundadores de los partidos regionales que han logrado participar y presentar candidatos consecutivamente en las cuatro ERM de 2002 a 2014 termina explicando de mejor manera las razones de la estabilidad de estas organizaciones. Su dirigencia no eran personas sin experiencia política y que participaban por primera vez en elecciones. Todo lo contrario, habían participado en más de dos procesos electorales previos, habían logrado ser elegidos como autoridades $y$, en algunos casos, tenían hasta experiencia previa en la constitución de organizaciones políticas de alcance local que luego transformaron en organizaciones políticas regionales.

\section{Conclusiones}

La volatilidad partidaria es una realidad en el sistema de partidos peruano, tanto a nivel nacional como subnacional. En cada proceso electoral de las ERM dos tercios de los partidos que se presentan no han participado en las elecciones previas (Seifert, 2016). Asimismo, un gran número de partidos regionales han participado a lo largo de las ERM. Frente a este escenario de alta volatilidad partidaria y gran número de partidos políticos regionales, existe un pequeño número (solo el $2 \%$ ) que ha logrado participar consecutivamente en todas las ERM.

¿Cómo lograron estas organizaciones políticas participar de forma consecutiva en las elecciones regionales y municipales? El presente trabajo buscó, en diversas dimensiones explicativas, usualmente relacionadas con la construcción partidaria, brindar una respuesta a esta interrogante. Muchas de ellas, como el diseño institucional, la geografía, los conflictos, no lograron responder satisfactoriamente esta pregunta. Ni siquiera el desempeño electoral pudo dar una respuesta comprensiva a esta interrogante, por la diferencia notoria en el éxito electoral que cada una de las organizaciones políticas tuvo a lo largo de las elecciones regionales y municipales.

El presente trabajo encontró que la dimensión que mejor responde a esta pregunta es la experiencia política previa. Esta fue comprendida como la participación en procesos electorales y/o haber ocupado cargos de elección popular. 
Así, la experiencia política previa que tuvo la dirigencia de estas diez organizaciones políticas fue importante al momento de constituirse como partido. Este origen sentó las bases para la construcción partidaria venidera y promovió el éxito electoral en algunas ocasiones.

$\mathrm{Al}$ analizar quienes han sido los presidentes y fundadores de estos partidos regionales, encontramos que en todos los casos (excepto el de Movimiento Independiente Regional FAENA) habían participado en más de dos procesos electorales previos. Asimismo, se habían desempeñado en diversos cargos de elección popular, como regidores, alcaldes provinciales o distritales. Por otra parte, en los casos de Cusco, Huánuco y Loreto, encontramos que la dirigencia había constituido organizaciones políticas de alcance local antes de las ERM 2002. Al convocarse a este nuevo tipo de elecciones, estos se sirvieron de su experiencia para transformar sus organizaciones locales en regionales o para constituir nuevas organizaciones políticas regionales.

Las elecciones regionales y municipales de 2002 fueron las primeras en su tipo, con nuevos actores regionales, nuevas autoridades a ser elegidas y en un proceso de descentralización que recién se estaba iniciando. En este nuevo e incierto territorio, la experiencia política previa jugaba un rol fundamental. Haber sido candidatos/as en elecciones pasadas les brindaba a la dirigencia de estas diez organizaciones políticas un conocimiento previo de cómo estructurar el partido y sus participaciones electorales. Asimismo, algunos habían participado electoralmente con partidos nacionales, lo que les daba un mayor conocimiento de cómo funciona una organización a nivel macro. Haber tenido una experiencia política previa, en este nuevo escenario que se inauguró con las ERM de 2002, fue clave para que la dirigencia pudiera sentar las bases de la organización que permitirían que perduraran en las siguientes elecciones.

En suma, en el caso de las elecciones a nivel subnacional que se han dado en el Perú desde 2002, la dimensión que logra explicar de mejor manera cómo los partidos regionales han logrado una estabilidad partidaria a nivel subnacional es la experiencia política previa que tuvieron los fundadores y la dirigencia del partido al momento de constituirlo. 


\section{BibLIOGRAFÍA}

Bellatin, P. (2014). Nuevos y viejos zorros: el movimiento regional Autogobierno Ayllu. Revista Argumentos IEP, 8(5), 91-98.

Cameron, M.y Levitsky, S. (2003).Democracy without parties? Political parties and Regime Change in Fujimori's Peru. Latin American Politics and Society, 45(3), 1-33. doi:10.1111/j.1548-2456.2003. tb00248.x

De Gramont, D. (2010). Leaving Lima Behind? The Victory and Evolution of Regional Parties in Perú. Tesis de Bachillerato no publicada, Harvard University, Masachusetts, Estados Unidos.

Defensoria del Pueblo. 2004 al 2014. Reporte mensual de conflictos del No 1 al 125. Recuperado de http://www.defensoria.gob.pe/temas.php?des=3\# $\mathrm{r}$

Incio, J. y Gil, R. (2016). Enraizamiento electoral en ámbitos subnacionales. Análisis de las organizaciones político-electorales peruanas (1963-2014). Revista Uruguaya de Ciencia Política, 25(1), 115-136.

Kolodny, R. (2012). Campaign finance and reform. En D. Coates (ed.), Oxford Companion of American Politics, (pp. 93-96). Nueva York, NY: Oxford University Press.

Levitsky, S, Loxton, J., Van Dyck, B. y Domínguez, J. I. (eds.) (2016). Challenges of party building in Latin America. Nueva York, NY: Cambridge University Press. doi:10.1017/ CBO9781316550564

Levitsky, S. (2003). From labor politics to machine politics: The transformation of Party-Union Linkages in Argentine Peronism, 1983-99. Latin American Research Review, 38(03), 3-36. doi:10.1353/lar.2003.0038

López, S. (1998). Crisis de partidos, nuevas mediaciones e interés público. En R. Urzua y F. Agüero (eds.), Fracturas en la gobernabilidad democrática (pp.121-135).Santiago de Chile: Universidad de Chile, CAPP.

López, S. (2001). Perú, 2000-2001: la transición democrática y el gobierno de transición. Lima, Perú: Comisión Andina de Juristas.

Lynch, N. (1999). Una tragedia sin héroes: la derrota de los partidos y el origen de los independientes. Lima, Perú: UNMSM.

Lynch, N. (2004). Diagnóstico y propuesta para consolidar un sistema de partidos políticos. En IDEA Internacional (ed.), Los nudos criticos de la gobernabilidad. Propuesta para un buen gobierno (pp. 53-74). Estocolmo, Suecia: IDEA.

Mainwaring, S. (1999). Rethinking Party Systems in the Third Wave of Democratization: The case of Brazil. Stanford, CA: Stanford University Press.

Mainwaring, S. y Scully, T. (eds.) (1995). La construcción de instituciones democráticas. Sistema de partidos en América Latina. Santiago de Chile: CIEPLAN.

Meléndez, C. (2008). Los efectos no esperados de la reforma política. Lecciones del caso peruano (2002-2006). Documento presentado en el Primer Congreso de Ciencia Política, organizado por la Universidad de los Andes, Bogotá, Colombia.

Samuels, D. (2006). Sources of mass partisanship in Brazil. Latin American Politics and Society, 48(2), 1-27. doi: 10.1111/j.1548-2456.2006.tb00345.x

Sartori, G. (2009). Partidos y sistemas de partidos. Madrid, España: Alianza Editorial.

Seifert, M. (2014). Colapso de los partidos nacionales y auge de los partidos regionales. Lima, Perú: Fondo Editorial PUCP.

Seifert, M. (2016). Volatilidad partidaria en el Perú: repensando la institucionalidad democrática. Revista de Ciencia Política Politai, 7(13), 35-51.

Tanaka, M. (2009). ¿En qué falló la Ley de partidos politicos y qué debe hacerse al respecto? Lima, Perú: IDEA Internacional.

Vergara, A. (2009). El choque de los ideales. Reformas institucionales y partidos políticos en el Perú postfujimorismo. Lima, Perú: IDEA Internacional.

Zavaleta, M. (2014). Coaliciones de independientes. Lima, Perú: IEP. 